\title{
OCIO Y PRÁCTICA DOCENTE EN MAESTROS Y MAESTRAS DE
} EDUCACIÓN PRIMARIA

LEISURE TIME ACTIVITIES AND TEACHING METHODS AMONG ELEMENTARY SCHOOL TEACHERS

Volumen 11, Número 2

pp. 1-28

Este número se publicó el 30 de agosto de 2011

Mayra Araceli Nieves Chávez

La revista está indexada en los directorios:

LATINDEX, REDALYC, IRESIE, CLASE, DIALNET, DOAJ, E-REVIST@S,

La revista está incluida en los sitios:

REDIE, RINACE, OEI, MAESTROTECA, PREAL, HUASCARAN, CLASCO 


\title{
OCIO Y PRÁCTICA DOCENTE EN MAESTROS Y MAESTRAS DE EDUCACIÓN PRIMARIA
}

\author{
LEISURE TIME ACTIVITIES AND TEACHING METHODS AMONG ELEMENTARY SCHOOL \\ TEACHERS
}

\begin{abstract}
Mayra Araceli Nieves Chávez ${ }^{1}$
Resumen: Este artículo ofrece resultados de una investigación sobre la vinculación entre ocio y práctica docente en maestros y maestras de educación primaria de la ciudad de Santiago de Querétaro, México. Se apoya en teorías sociológicas y educativas: Heller, Bourdieu, Freire, Gramsci; así como autores del ocio: Sue y Cuenca. Describe datos obtenidos de un estudio de caso sobre las vivencias de ocio, desde una narrativa fenomenológica, obtenidos de entrevistas. La etnografía en el aula se empleó para describir la práctica docente e identificar las estructuras de ésta. La hermenéutica auxilió en la interpretación de estos datos y en la construcción de los siguientes tipos ideales de ocio-práctica docente: un ocio aburrido se asocia a una maestra autoritaria, o, a un maestro que renuncia a educar; un ocio creativo a maestras y maestros emancipadores; un ocio híbrido a maestros y maestras en ciernes, que aún no definen un tipo de práctica docente. Se concluye que el ocio sí está presente en la práctica docente, que no hay fronteras per se entre lo público y privado. El maestro y maestra es más que un profesionista cuando está frente a grupo, es una persona que pone en juego lo que es y tiene. El ocio imprime una característica singular a la práctica docente como apropiación de conocimientos y cultura.
\end{abstract}

\section{Palabras clave: OCIO, PRÁCTICAS DE OCIO, PRÁCTICA DOCENTE, VIDA COTIDIANA, MÉXICO}

\begin{abstract}
This article contains the results of a research study on the tie between leisure time activities and teaching methods among elementary school teachers in the City of Santiago de Querétaro, México. It is based on sociological and educational theories: Heller, Bourdieu, Freire, Gramsci, as well as authors who wrote about leisure time: Sue and Cuenca. It describes data obtained from a case study on leisure time activities, from a phenomenological narrative, obtained in interviews. Ethnography in the classroom was used to describe teaching methods and identify their structures. Hermeneutics aided in the interpretation of this data and in the construction of the following ideal types of leisure time-teaching methods given as results of the research: boring leisure time is associated with an authoritarian teacher or a teacher not interested in educating; creative leisure time with emancipative teachers; hybrid leisure time with new teachers who have not yet defined their teaching method type. It is concluded that leisure time activity is present in teaching methods, that there are no borders per se between the public and the private. The teacher is more that a professional when he/she is in front of the class; he/she lays out what he/she is and has. Leisure time activities leave a singular imprint on teaching methods as an appropriation of knowledge and culture.
\end{abstract}

Key words: LEISURE TIME, LEISURE TIME ACTIVITIES, TEACHING METHOD, DAILY LIFE, MEXICO

1 Estudiante de doctorado en educación en el Centro de
Estudios Superiores Nova Spania, Morelia, Michoacán, México.

Dirección electrónica: mayra marzo6@hotmail.com

Artículo recibido: $1^{\circ}$ de febrero, 2011

Aprobado: 18 de agosto, 2011 


\section{Introducción}

El abanico de la investigación educativa abarca temas como la cuestión pedagógica, la vida en las aulas, los conflictos sindicales, el currículo, evaluación, relaciones institucionales, entre otras. Tales investigaciones no han abordado la perspectiva sobre la vida privada de la población docente.

Estudiar el ocio, como parte de la vida privada, es investigar a los maestros y las maestras no solo como personas trabajadoras, sino, como personas con gustos y preferencias para vivir el ocio. La importancia del ocio radica en que es un tiempo en el cual se realizan actividades en libertad; actividades como ver televisión, escuchar, la radio, leer, asistencia a academias y participación social, autoformación. El ocio es parte de la formación de las personas y de un estilo de vida (Sue, 1992 y Bourdieu, 2002).

El ocio como formación y enriquecimiento personal, complementa la formación profesional de los maestros y las maestras. Vincular el ocio con la docencia reconoce que, la práctica docente se estructure en parte por la formación académica, por los conocimientos propios, así como por estrategias y recursos que el profesorado adquiere a lo largo de su vida. El aula es el espacio donde, maestros y maestras, crean y recrean actividades que se caracterizan por su relativa continuidad, dando forma a estilos en la práctica docente.

El presente artículo se sustenta en las teorías sociológicas de Ágnes Heller, Pierre Bourdieu, en teorías educativas de Gramsci y Freire. Para el ocio se retoma a Sue y Cuenca. Se describen vivencias de ocio y práctica docente. Se construye una tipología: un ocio aburrido se asocia al personal docente autoritario o que renuncia a educar; un ocio creativo al personal docente emancipador; un ocio híbrido al personal docente en ciernes, que aún no define un tipo de práctica docente. Se concluye que el ocio sí está presente en la práctica docente y que la vida privada es el espacio para ser quien se quiere ser.

\section{Ocio y práctica docente, actividades que integran la vida cotidiana de los maestros y las maestras}

Cuando una nueva persona llega a este mundo lo encuentra ya constituido con manifestaciones culturales propias y concretas de su tiempo y espacio; las cuales requiere apropiarse, para la interacción social. Estos aprendizajes se realizan en grupos como la familia, la escuela, comunidades religiosas o amistosas, entre otras. 
De este modo, cuando la persona se apropia del mundo, puede reproducir y producirse a sí misma, así como a lo social, por medio de actividades de apariencia de sentido común, en las actividades y trabajos diarios. La vida cotidiana es la repetitividad de actividades que conducen a la reproducción de lo existente, que implica dedicarle un tiempo y espacio a cada actividad.

Para Heller (1985) estas actividades son impuestas y, al mismo tiempo, asumidas por la humanidad, que objetivan capacidades manipulativas e intelectuales, sentimientos, ideas e ideologías. Estas actividades son singulares en cada persona; las formas de actuar, sentir y pensar difieren por las condiciones sociales, materiales y temporales de cada hombre y mujer.

\subsection{Lo público y lo privado como parte integrante de la cotidianidad}

En la actualidad la vida cotidiana cuenta con una organización y diferenciación de espacios y actividades, que Aries (2001) identificó como lo público y privado. El trabajo es el espacio público y la vida doméstica la zona privada. El hogar es la frontera con la vida pública, la vida privada, señaló Certeau (1999), es el lugar protegido donde se da la relajación de la presión social y donde se aprenden las artes de hacer. El hogar es el espacio donde se realiza la reproducción de las personas, y donde se da la apropiación del mundo. La vida doméstica no abarca la totalidad de la vida privada, existe una privacidad más allá del círculo familiar que es la vida personal, el espacio privado de lo privado; se compone de actividades extra-familiares que irrumpen en el espacio público para el encuentro con aquellos con quienes se desea compartir la cotidianidad.

En la sociedad moderna Lefevre (1984) indica que aparece una categorización del tiempo: el tiempo obligado que es el laboral, el tiempo libre que es el ocio y, el forzado, empleado en exigencias sociales, burocráticas y fisiológicas. La clasificación del tiempo es parte de la organización de la vida cotidiana. El ocio se despliega en la zona de vida privada.

El ocio tiene una concepción distinta en el tiempo y en el espacio social. Para los griegos, refiere Sue (1992), el ocio era instrucción, pero sólo para una casta, ocio y trabajo no tienen relación. En la época romana ocio y trabajo se complementan, el ocio es relajación. En la Edad Media, escribe Gómez (1988), el ocio se enclaustró en el monasterio, la vida del hombre era el trabajo. En la sociedad preindustrial el ocio no existe, existe la inactividad laboral por cuestiones climáticas, religiosas o azarosas y, el ocio es para una casta ociosa. 
Con la reforma protestante, observa Weber (1985), el ocio es un derroche del tiempo. En la sociedad industrial no hay liberación del trabajo, sino una presión del trabajo sobre los hombres, la ociosidad es un crimen.

En la sociedad moderna el ocio, nos dice Cuenca (2000), es una vivencia del tiempo libre, es parte de la realización personal fuera del contexto laboral, así como un medio para dotar de sentido la existencia. El ocio es parte de actividades generadoras de placer y goce, que ayudan a la recreación y creación de la persona.

Para algunos teóricos el ocio es un medio para la realización personal, en el sentido común, la experiencia del ocio es diversa: se experimenta como el no hacer nada, hacer cualquier actividad fuera de los compromisos laborales, o desconectarse de los compromisos cotidianos y realizar actividades gratas para la persona. Algunos maestros y maestras no sienten que tengan tiempo para el ocio porque la cotidianidad está llena de compromisos y lo que les agrada hacer no tiene cabida. La percepción del ocio como actividad opuesta al trabajo está presente. Falta concebirlo desde una visión integral: desde no hacer nada, hacer lo que agrada, cuidar la salud, la sociabilidad, las actividades altruistas, hasta la autoformación y formación. El ocio debe pensarse y vivirse como un proceso formativo de la entera vida de la persona y de un proceso de toda la vida.

\subsection{Actividades de ocio}

El ocio, como actividad, tiene rasgos básicos: contenido, temporalidad y actitud. Clasificar las actividades no es sencillo por sus rasgos básicos y sus fines, según Sue (1992) se puede hablar de actividades físicas, prácticas, culturales, sociales, además de sumarles políticas y religiosas.

Sue (1992) y Cuenca (2000) señalan que las actividades físicas van desde del deporte, las salidas al campo o áreas verdes, la jardinería, la cocina, hasta la mecánica. Las culturales como escuchar la radio, ver la televisión, leer, salir al teatro o al cine, producir o admirar el arte. Las sociales implican también relaciones extra-familiares como relaciones con amistades y amores, asistir a fiestas, hacer llamadas telefónicas, pertenecer a academias culturales, tomar café, salir a eventos deportivos o musicales, salir a bailar, al bar o restaurante, ir a fiestas tradicionales, visitar al centro histórico. Las políticas sería la militancia sindical o partidista, las reuniones de carácter político, asistir a desfiles cívicos. Por último las religiosas, la asistencia al culto. 
Estas actividades tienen la función del descanso, la diversión, el desarrollo intelectual y artístico, y la sociabilidad (Sue, 1992). El tiempo libre, nos dice Cuenca (2000), puede carecer de alternativas y verse inmerso en la alienación, aburrimiento y sopor del tiempo, de ahí que hablamos de un ocio aburrido y programado.

El ocio debe ser elegido en libertad; cuando se realizan actividades que otros sugieren como las que implican la industria del entretenimiento ${ }^{2}$, entonces sólo se es consumidor y puede ser esparcimiento, pero corre el riesgo de no ser un ocio creador, creativo y provechoso para el crecimiento y desarrollo personal.

El ocio se despliega en compañía de la familia, amistades, personas con quienes se trabaja y de forma personal. Por familia hay que entender cualquier parentesco biológico y social en sus diversas configuraciones de las relaciones sociales. Los amigos y las amigas configuran una relación de iguales con un deseo común, siendo una relación privada y personal que se agota con las personas relacionadas. Existen otras relaciones secretas y clandestinas, dice Requena (1994), como los amantes, que se reducen a las personas involucradas. La relación consigo mismo, la relación personal, es lo privado de lo privado, es la distención del lazo familiar y social, es el apartamiento del mundo, como lo menciona Martí (2007), es el repliegue sobre sí mismo, el ejercicio de la intimidad.

\subsection{El ocio y estilo de vida}

Antes se mencionó que la vida cotidiana es la repetitividad de actividades que finaliza en la reproducción de lo existente o, en la producción de algo nuevo y que implica dedicarle un tiempo y un espacio a cada actividad. Estas actividades para que reproduzcan lo social deben tener una función social, afirma Heller (2002), por ejemplo, la ciudadanía, la profesión o actividad laboral, y las responsabilidades familiares. La vida cotidiana no absorbe por entero, esto es: no es sólo reproducción y satisfacción de necesidades para la sobrevivencia; existen no sólo las personas particulares preocupadas de sí mismas, también están aquellas preocupadas por intereses genéricos que suspenden su particularidad, estas son personas individuales, afirma Heller (1985).

\footnotetext{
${ }^{2}$ La industria del entretenimiento son aquellas empresas que producen cultura de forma masiva, que tiene como base un conjunto de clichés sobre la forma de pararse frente a la vida. Entre estas empresas productoras de cultura se encuentran los medios masivos de comunicación, el cine, música, videojuegos, algunas casas editoriales, podríamos incluir las tecnologías modernas, tal como el internet, la telefonía móvil.
} 
Dichas actividades objetivan un estilo de vida, porque son formas duraderas de ser y valorar que se encarnan como propias a lo largo de la vida. Son apropiadas en el proceso de socialización, proceso que constituye una historia que fue vivida por otros, pero que es apropiada en el hoy. Estas actividades cotidianas como trabajo y descanso se despliegan en lo público y lo privado. Se les denomina prácticas, porque su motivación y orientación parte de estas formas de ser y valorar, a lo que Bourdieu nombró habitus, que son la estructura de las actividades cotidianas.

El habitus, como lo menciona Bourideu (2002), es la socialización que se adquiere en el campo, es decir, en un sistema de relaciones que determinan la lógica de la realización de las actividades. Esta socialización encarna el pasado e incorpora elementos nuevos a la cotidianidad dentro de los campos. Esto implica que las formas de auto reproducción (particular) y producción (individual y genérica) se modifican en el tiempo y espacio. En el campo se reproduce la cotidianidad, tejida entre lo público y privado, a la par que se produce la vida no cotidiana, por ser un espacio de aprendizaje y despliegue de prácticas.

El habitus es la brújula de las prácticas cotidianas y la disposición que organiza e impulsa cada actividad acorde a lo querido y no querido, a lo admisible e impropio por los integrantes de los campos. Para Bourdieu (1991) es una disposición de lo pensable e impensable ajustado a la clase social, género, raza, etnia, contexto sociocultural, político e ideológico, entre otras condiciones y exigencias de la cotidianidad. En cada campo se ponen en juego bienes simbólicos, una identidad, actividades válidas y prohibidas, el prestigio o, lo rechazable. Quienes pertenecen al campo luchan por adquirir los bienes simbólicos ${ }^{3}$. Aquello que los mueve a invertir sus fuerzas en la adquisición de bienes es la illusio, según Bourdieu (1995), es el interés en el juego y la creencia en el valor de los bienes simbólicos en juego.

La función social esperada por la posición social es cumplida gracias a la illusio por el sentido que le imprime a las prácticas. Cada práctica cotidiana es objetivación de la illusio. El ocio como práctica es una objetivación del habitus en complicidad con el campo y motivado

\footnotetext{
${ }^{3}$ Los bienes o capitales que se ponen en juego o se acumulan son de orden económico, cultural institucionalizado como la obtención de títulos académicos, diplomas o reconocimientos, existe un capital cultural que se objetiva en la acumulación de arte u objetos extraordinarios que son reflejo del gusto. También hay un capital simbólico que tiene que ver con la honradez, honor, solvencia, generosidad, etc. Por último el capital social que se adquiere a través de la red de relaciones que se establecen con los demás jugadores del campo (Bourdieu, 2002, 1990, 1995). El capital en general o bienes simbólicos se identifican en los conocimientos habilidades, creencias, objetos decorativos, relaciones sociales, poder, prestigio, reputación, entre otros.
} 
por la illusio. El ocio puede estar orientado a la satisfacción de necesidades personales o particulares como el descanso, la diversión y el esparcimiento o, bien, orientado a actividades genéricas tal como la ciencia, la política y el arte que menciona Heller (1985). El ocio también es producto del gusto. El gusto, nos dice Bourdieu (1999) es la confluencia entre un quienes ofertan y demandan. Por el gusto se pertenece a un campo y se acumulan bienes y el campo se vuelve un mercado por los bienes que definen el valor en relación a otros campos, esto permite la distinción con otros campos por los distintos estilos de vida.

\subsection{Las prácticas de ocio y su vinculación con la práctica docente}

La cotidianidad se desarrolla entre lo público y lo privado, no hay frontera per se, de ahí que los maestros y las maestras no sólo sean trabajadores, sino también personas con una vida privada. Como personas ejerciendo la profesión de enseñar cuentan con conocimientos profesionales, como personas con una vida privada adquieren conocimientos, recursos y estrategias que aprenden en su tiempo libre. El trabajo frente a grupo requiere que dispongan de todas las capacidades obtenidas en las zonas públicas y privadas, es decir, “... utilizan e integran los diversos conocimientos sociales y culturales que poseen como personas más allá de su formación profesional' (Mercado, 1986, p. 69). Estos conocimientos son la percepción y asimilación del proceso de socialización y, según éstos se vivirá el tiempo de ocio y la práctica docente.

En el ocio se pueden presentar dos tendencias: 1) momento creativo y dinámico, de desarrollo personal y, 2) momento aburrido y organizado por la industria del entretenimiento, cargado del consumo de una cultura de masas; cultura que despierta el interés de la mayor parte de la población que las practica y consume; cultura que no sofoca del todo a la cultura tradicional - esa que expresa formas respetables y verdaderos valores culturales y patrimonio de un pueblo-, y a la alta cultura -vida académica y artística- según Gonzalbo (2006). La cultura de masas es el advenimiento de la vida de consumo que estereotipa gustos y prácticas cotidianas. El ocio se vuelve consumo y eso lo hace, en algunos casos, organizado y enajenante, porque “...alienta o refuerza la elección de un estilo... que desaprueba toda cultura alternativa" (Bauman, 2007, p. 78).

La crítica del consumo del ocio organizado es que enreda en la lógica del mercado capitalista y obstruye la relación consciente sobre el conocimiento de las verdaderas necesidades particulares y los intereses escabrosos del mercado. El ocio se convierte en 
consumo porque es invertir "...en todo aquello que hace al "valor social" y la autoestima" (Bauman, 2007, p. 83).

Lo importante no es la satisfacción de proyectos personales, sino convertirse en consumidor para existir, obstaculizando la humanización del hombre a pesar de ser una cultura híbrida. Es híbrida porque comercializa el arte culto y lo pone en manos de todos, Para García Canclini (2004), es retomar bienes simbólicos de la cultura tradicional y de mezclar lo artesanal con lo industrial; así como una hibridación entre lo viejo y lo nuevo.

El riesgo de un ocio aburrido es su posible vinculación teórica con un maestro o una maestra que renuncia educar, o ambos a ser autoritarios. Un ocio aburrido puede provenir de necesidades particulares del maestro o la maestra. Aunque esto no sea general ni absoluto porque se puede presentar, en ambos, que lean, se informen y se formen, por el puro gusto de satisfacer necesidades particulares o personales. Estos bienes que acumulan son instantáneos, afirma Bauman (2005), y su uso es desechable, no es una inversión, se pierde el sentido de acumular "para siempre" y, no tiene uso a largo plazo, es sólo presunción.

El ocio instantáneo no es acto de conocimiento del mundo ni personal, la fugacidad obstruye la capacidad de reflexión y es probable que algunos maestros y algunas maestras, nos dice Gramsci (1999), improvisen en el aula, o estén con pereza fatalista, con indisciplina intelectual, además de irresponsabilidad moral e intelectual, características de la renuncia a educar. También se puede presentar una comunidad de maestras y maestros autoritarios, según Pansza (1993), que reprimen el cuerpo y las ideas, como único camino viable para educar, y por ello, establecen límites y controles al cuerpo y a las ideas, y como consecuencia obtienen un orden por encima de las necesidades del alumno y de la alumna.

El ocio creativo se vincula con ciertas maestras y maestros emancipadores; un ocio genérico posibilita la visión crítica del mundo, el autoconocimiento, una apertura con las demás personas. Lleva a asumir responsabilidades morales, reconoce necesidades particulares e individuales y sabe poner distancia entre estas necesidades. En libertad opta entre los valores que prescribe el mundo y los valores personales.

Estas maestras y maestros con un ocio que emancipa, son emancipadores en el salón de clases porque aprendieron y sienten la necesidad de “... revelar a los alumnos [su] capacidad de analizar, de comparar, de evaluar, de decidir, de optar, de romper" (Freire y Faundez, 2002, p. 92). Enseñan con una actitud crítica ante el mundo, en un ambiente de 
libertad y de diálogo, se interesan por descubrir las percepciones de las alumnas y los alumnos, no imponen sus ideas y procuran establecer nuevas formas de relación social.

Así como hay un ocio híbrido que presenta una convivencia entre lo culto y popular, se presentan maestras y maestros con una tendencia no definida en las prácticas de ocio. Gustan del ocio creativo y del ocio aburrido, su práctica docente está en ciernes. En ciernes porque no renuncian del todo a dejarse conducir por la tradición y aceptan pautas de la vida moderna; necesitan y buscan el ejemplo de los expertos y las expertas, se dejan seducir por las nuevas formas de educar, y como dice Gramsci (1981), se encuentra en la encrucijada de la lucha de generaciones. Se encontró que ellas y ellos tienen rasgos de la escuela tradicional -verbalismo, verticalismo-, y al mismo tiempo rasgos emancipadores, dialogan y luchan por establecer relaciones horizontales, delegan responsabilidades a la población estudiantil, no se limitan a reproducir el texto, sino que van invitan a reflexionar la realidad, no se quedan en el verbalismo.

El ocio como aprendizaje y proceso de acumulación de conocimientos sociales y culturales -aún así sean los de una cultura de masas- es apropiación del mundo y reproducción y producción de la cotidianidad. La práctica docente es la puesta en juego del capital acumulado tanto de los espacios públicos como de los privados.

\section{Metodología}

El objetivo principal del artículo fue responder a la pregunta: cómo encarnan el tiempo de ocio maestras y maestros de educación primaria y su vinculación con la práctica docente.

Para alcanzar tal objetivo se plantearon los siguientes objetivos particulares: 1) Indagar en los tipos de prácticas de ocio, 2) Identificar los espacios donde se realizan las prácticas de ocio, 3) Elaborar una clasificación de las prácticas de ocio para establecer la relación con la práctica docente y, 4) Describir la práctica docente. Se empleó una metodología con carácter cualitativo, se diseñó un estudio exploratorio y coyuntural.

Se optó por un estudio de caso que permitiera explorar la vida privada. Los estudios de casos, afirma Orozco (2000), tienen la bondad de ser flexibles, lo importante es tomar lo distintivo que permita hacer aproximaciones al hecho que se estudia, son un ejemplo de un contexto mayor; ello justificó no recurrir a muestras estadísticas.

La información empírica se obtuvo de maestras y maestros de educación básica de la ciudad de Santiago de Querétaro, México. El criterio de elección estuvo condicionado a ser 
parte del profesorado en servicio; así como que tuvieran más de 20 años de antigüedad, y otros que fueran de nuevo ingreso para comparación generacional. Fueron cuatro maestras y cuatro maestros los que configuraron el estudio de caso: cuatro con antigüedad y cuatro de nuevo ingreso, de cada grupo, dos de ellos fueron hombres y dos mujeres, con la finalidad de tener una población equitativa.

El primer momento de trabajo de campo fue la descripción de las actividades de ocio y de la práctica docente. La etnografía y el método fenomenológico permitieron recuperar la experiencia de vida, tal y como son vivenciadas y percibidas por los maestras y los maestros, en el entretejido de lo público y lo privado; porque esta experiencia es el conocimiento de la vida misma como lo consideran Husserl, (1990) y Morín (2002). Para esto se buscó valorar las prácticas cotidianas, oír detalladamente la experiencia del ocio en tiempos y espacios de las actividades, así como describir con minuciosidad la práctica docente.

La descripción de la vivencia del ocio consistió en relatar estilos de vida (actividades y espacios) por medio de una entrevista que recogió lo siguiente: actividades y espacios de realización de actividades de tiempo libre, y el cómo de su realización. También se preguntó por la formación docente y condiciones materiales de vida.

La etnografía se utilizó para la descripción de la práctica docente. Las prácticas registradas fueron: entrada al aula, pase de lista, exposición del tema, asignación de tareas, motivación al trabajo grupal e individual, reglamentación y disciplina, medición y distribución del tiempo. Se buscó crear una imagen de la maestra y el maestro fiel y realista de su trabajo al interior del aula como lo expresa Martínez (1998), que permitió identificar las estructura de la práctica docente.

La sistematización de la observación de la práctica docente y la elaboración de una estructura común representativa de las experiencias del ocio, fue un trabajo que requirió de la interpretación de éstas. Este segundo momento estuvo regido por la hermenéutica. Se profundizó, como lo propone Bourdieu (1991), en la observación de la interiorización; en adelante cuando se hable de las maestras y maestros se debe entender como la estructura estructurante, se refiere a la interiorización que se exterioriza. El método hermenéutico fue un auxiliar al

establecer el modo en que son adoptadas y mantenidas [las prácticas de ocio y la práctica docente] dentro de ciertas condiciones; [así como] de su término de referencia... en las condiciones que las torna posibles... [y la] dirección [que] 
representan... [en] la toma de decisiones frente a tales condiciones. (Weber, 1982, p.30)

La finalidad fue describir para luego interpretar y comprender el motivo que orienta las prácticas cotidianas de ocio y trabajo “...basándose en los datos ofrecidos por los "hechos”... y en fines dados, deduce para su acción las consecuencias... inferibles... acerca de la clase de "medios" a emplear" (Weber, 2002, p. 6). Fue captar el fin y hacerlo comprensible al desarrollo de la acción, captar el sentido de conexión entre lo interior del motivo y lo exterior de la práctica, esto permite comprender el resorte que impulsa a realizar las prácticas de la vida cotidiana.

El tercer momento del trabajo de investigación fue la construcción de tipos ideales. Gracias al concepto metodológico de tipo ideal de Max Weber, con esta conexión de sentido fue posible conjuntar formas de ser y valorar, que revelaron tener mayor similitud de sentido con los tipos ideales de ocio creativo o aburrido y maestro autoritario, el que renuncia a educar, el emancipador y el que está en ciernes. Estos tipos ideales no existen de forma pura en la realidad, pero sí son una muestra de cómo sería la realidad, si siguiesen la misma exactitud de los términos de la teoría, como lo propone Weber (2002).

Tanto los tipos ideales como el resultado empírico no son la realidad, son una aproximación; los resultados son la tendencia recurrente que se aproxima al tipo ideal con mayor conexión de sentido entre la práctica y la motivación del ocio y práctica docente. Estos tipos ideales se agruparon sobre la base de bienes simbólicos: tipo de lectura, programas de televisión, música, deportes, entre otros, y el tipo de práctica docente.

\section{Análisis de los estilos de ocio}

La vida cotidiana revela estilos de vida que están sujetos a las condiciones de existencia material como es el tiempo laboral, el estado civil, la formación profesional, el tipo de vivienda, el ingreso. Por ejemplo, hay maestras y maestros que tienen un año de servicio, o 24 años de experiencia. Otras y otros trabajan una plaza, o doble jornada y con categoría en carrera magisterial. Hay quienes han hecho la normal superior (formación para la educación secundaria). En su vida privada son esposas o esposos, hijas o hijos, hermanas y hermanos. Son madres o padres de hijos en edad escolar. Son madres o padres pero están separados de la pareja. Además entablan otras formas de relación social con amistades, novias o novios o amantes. Relaciones que contribuyen a determinar las prácticas de ocio. 
La condición profesional de maestras y maestros les hacen compartir ciertas características en las condiciones materiales de vida, campos que homogeneízan y que orientan las tendencias del ocio. Dos tendencias principales se presentan en los estilos de encarnar el ocio: 1) ocio en la esfera familiar y, 2) ocio en la esfera personal y, en menor medida un ocio con amistades y personas con quienes se trabaja. Estas tendencias no abarcan ni explican lo totalidad de la realidad, son aproximaciones, que pueden presentar variaciones según las trayectorias personales y el contexto social existente. Cabe aclarar que, estudiar el profesorado de nuevo ingreso, lleva a una comparación generacional, el ocio familiar y personal están presentes en ambas generaciones, sólo que una tendencia es la que hace la singularidad en una generación y en otra.

\subsection{Ocio en la esfera familiar}

El tiempo de ocio en la esfera familiar -tiempo que se pasa con la esposa o esposo, hijas e hijos, o con los padres y hermanas y hermanos-, presenta principalmente tres momentos: tiempo libre durante la semana, el descanso laboral del fin de semana y el tiempo de vacaciones.

Durante la semana se reduce, generalmente, a ver la televisión y platicar con la familia. Los fines de semana en juegos de mesa, turismo regional, paseos por áreas verdes y asistencia al culto religioso. El tiempo vacacional de verano, tiempo prolongado de vacaciones, se distribuye en cursos de verano, vacaciones en la playa, permanecer en casa con las hijas o los hijos, y visitar a familiares y amistades. Se presentan actividades con una periodicidad aproximada de un mes como las salidas al teatro de comedia, cine y espectáculos infantiles como el circo.

Las características del ocio familiar son: un ocio creativo y organizado que busca reparar la fuerza de trabajo por medio del descanso, diversión y sociabilidad con la familia, es un ocio híbrido entre la tradición y el uso de las nuevas tecnologías (cine, televisión, DVD) y el viaje turístico, así como la asistencia al teatro. Es un ocio creativo porque los juegos de mesa permiten objetivar capacidades personales, y suspender por un momento las responsabilidades cotidianas, porque es un medio que “... desarrolla o moviliza capacidades humanas sin ninguna consecuencia" (Heller, 2002). Estás capacidades humanas se siguen desarrollando en la conversación cara a cara, como forma de intercambio instantáneo y espontáneo de experiencias cotidianas, como forma de expresar sueños, anhelos y 
problemas. Este tipo de ocio es una forma de socializar y estrechar lazos familiares, de interiorizar capital cultural como valores, sentimientos y creencias que comparten como grupo social. Es así un entrenamiento para expresar y escuchar al otro en contextos sociales más extensos. Aprendizaje que se refuerza en los paseos familiares, en convivencias 0 fiestas con la familia extensa, en donde se ensancha el horizonte de la relación social.

El ocio que tiene que ver con la televisión y el cine, es un ocio organizado, en parte es un ocio aburrido, por lo clichés que envuelven a las históricas fantásticas, de superhéroes y de comedia ramplona, producto de la industria del entretenimiento y cultura de masas. Homogeneíza formas de ser y de pensar por medio de símbolos y mitos fáciles de transferir a cualquier ámbito de la cotidianidad. La asiduidad a la televisión está condicionada por la dinámica familiar, porque acompaña la comida o cena, con las telenovelas y noticieros. El consumo televisivo, en su mayoría, es un consumo pasivo y sumiso que tiene como fin recuperar las fuerzas de trabajo, encontrarse y relacionarse con los miembros de la familia y de informarse sobre el mundo. Contradictoriamente hay un cine con temática diferente que aborda dilemas propios de la existencia como el cine de arte, que ofrece una visión crítica de la realidad. Para aquellas maestras y maestros que como padres de familia fomentan este tipo de cine y televisión con los hijos, es una forma de socialización que escapa a la producción de masas. Otras maestras y maestros no asisten al cine ni ven programas televisivos por la mala oferta, pues reconocen que son una manera grotesca de resaltar la miseria y depravación humana ${ }^{4}$, esta percepción va de la mano con la illusio de la maestra o la maestro, ambos tienen una imagen de la persona que se contrapone con la presentada en el cine.

El culto religioso es movido por la illusio de humanización. Es un medio para darle sentido a la vida y motivación para cambiar las condiciones de la vida material y dotarlos de un código moral ${ }^{5}$. Es una forma de trascendencia de recrearse a sí mismo, de hacerse dueño de sí, así como de motivación a prácticas genéricas en la vida cotidiana. Es ayuda para enfrentar las dificultades de ser buena madre, esposa y maestra, o buen esposo, padre y

\footnotetext{
4 "La mayoría de programas, telenovelas, películas... nada más como que dañan al ser humano, violencia, sexo, fraude" (Entrevista, 11 de marzo de 2009).

5 "siempre he sido persona que me aboco a la religión católica, me he separado un poquito por el trabajo, pero siempre le dedico su espacio al menos cada 8 días una hora es, para mí, una ayuda para vivir mejor, estar en paz con los demás" (Entrevista, 11 de marzo de 2009).
} 
maestro ${ }^{6}$. La illusio de la maestra o maestro se ve reforzado por la illusio de creyente. Hay quienes asisten por tradición, por compromiso social y por ser parte de la formación de las hijas e hijos. El culto religioso es un ocio creativo mientras induzca la reflexión y a nuevas formas de concebir y relacionarse con el mundo.

El ocio de fines de semana como ir al teatro, es un ocio que comprende sociabilidad con grupos más extensos que la familia. Es descanso y formación humana que a través de una puesta en escena lleva a la reflexión de la vida misma.

Asistir al circo es una expresión de romper con la lógica del orden cotidiano, es un momento de evasión de lo cotidiano y expresión de diversión; ocio que lleva al descanso necesario en la vida cotidiana, por la sensación grata de reír.

Los tiempos prolongados de liberación de trabajo son las vacaciones, el profesorado tienen tres periodos vacacionales: Navidad, Semana Santa y de verano. Navidad y Semana Santa son un tiempo de permanecer en casa con la familia y llevan impreso un sentido religioso. Es tiempo de circular afectos y reforzar creencias religiosas. Ambos momentos vacacionales son un tiempo para reparar la fuerza de trabajo y estrechar lazos familiares.

En verano visitan a familiares y amistades, van de vacaciones a la playa y toman cursos de verano. Visitar a familiares y amistades es parte de la vida social de las maestras y los maestros. Es un ocio creativo que implica la objetivación de sentimientos por medio de la comunicación y las actitudes, que permiten abrir el círculo de relación social más allá de la familia y el encuentro con demás personas.

La playa es descanso y diversión familiar, rompe la rutina de lo cotidiano, así como tiempo de contemplación y disfrute de la naturaleza ${ }^{7}$. Los cursos de verano son un medio de profesionalización ${ }^{8}$, motivados por la illusio de ser mejor personal docente. Para otros

\footnotetext{
6 "En el catolicismo me enseñaron que debo reconocer la dignidad de los demás, yo en mi trabajo, busco dignificar a los niños, los respeto, me intereso por su vida familiar, hablo con ellos de sus sueños e intento explotar sus capacidades, que adquieran seguridad en ellos mismos y que compartan lo que tienen" (Entrevista, 31 de marzo de 2009). "Voy a misa, porque es una educación para los hijos, mientras crecen, para que agarren algo bueno y para que tengan un sentido en la vida y para darle gusto a mi esposa" (Entrevista, 20 de mayo de 2009).

7 "Escogemos el mar para vacacionar, porque los hijos corren libres en la arena, jugamos en la playa, nos bañamos en el mar, y hacemos lo que queremos" (Entrevista, 26 de marzo de 2009); otro dice: "En el mar, descansamos, contemplamos y escuchamos el mar, puedes dormir, pensar, cargar la pila para regresar a casa y gozar de la naturaleza" (Entrevista, 20 de mayo de 2009).

8 "Asisto a los cursos de verano, para poder dar mejor mi clase, busco cursos en los que siento que me falta saber más y luego vengo con mis niños y trato de aplicar lo que aprendí" (Entrevista, 31 de marzo de 2009).
} 
maestras y maestros los cursos de verano no forman parte del tiempo de ocio, más bien son parte del escalafón en la carrera docente ${ }^{9}$. La constancia de asistencia al curso es un capital cultural institucional que permite el ascenso en el escalafón; para otros es eso y más, es la oportunidad de nuevos conocimientos, de renovarse, de compartir con otras personas y de sociabilizar.

El ocio familiar deja al descubierto que la cultura de masas no a todo el profesorado, investigado, ni a todo lo absorbe por entero, hay espacios para la creatividad y para objetivar sentimientos e ideas entre el grupo familiar. Prácticas que acumulan capital cultural y simbólico como los valores familiares; además de habilidades y conocimientos y la fortificación de las relaciones sociales entre la familia y otros grupos sociales. Existe una diferencia generacional, entre el profesorado de nuevo ingreso y con antigüedad. El personal docente de nuevo ingreso tiene la illusio de construir una familia propia y el tiempo de ocio queda condicionado por esta necesidad, lo que lleva a un retiro del compromiso social y a un repliegue familiar. A diferencia del profesorado con antigüedad, que busca el compromiso social.

\subsection{Ocio en la esfera personal}

Las maestras y los maestros con antigüedad pasan más tiempo consigo mismos, dedican mayor tiempo al ocio personal, la tendencia del profesorado recién llegado es menor. Este ocio personal tiene dos tendencias generales: 1) el ocio personal de maestras y maestros con antigüedad es un ocio que consume pero lleva a la producción y, 2) el ocio personal de maestras y maestros de recién ingreso es más consumista y reproductor de nuevas tecnologías, artículos de deporte y visitas a cafeterías.

El ocio personal del profesorado con antigüedad, tiene tres características principales: 1) Se organiza en función del compromiso social y del interés de incidir en el campo educativo y en las condiciones materiales de la vida de la comunidad magisterial. La illusio de este ocio se materializa en espacios externos al hogar y fuera del círculo familiar. 2) Es un ocio que se encarna en la esfera de las amistades, compañeros y compañeras de trabajo

\footnotetext{
9 "Asisto a los cursos que no puedo evitar, a mí no me gusta estudiar, voy cuando es necesario y cuando tienen valor escalafonario, tengo una familia que mantener y soy el responsable de llevar el dinero, pero a mí no me gusta estudiar, no lo considero necesario para cumplir con mi trabajo" (Entrevista, 24 de marzo de 2009).
} 
para la reflexión y discusión. 3) Es un ocio consigo mismo en búsqueda de soledad para la

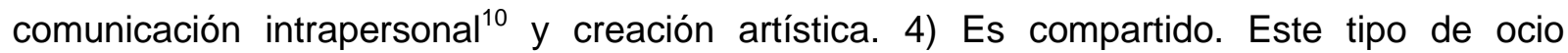
adquiere una tendencia individual, emancipadora tanto para quienes lo encarnan, como para las demás personas que conforman el campo educativo y la sociedad misma, tal como son la práctica de la actividad política y la creación artística.

El ocio personal desplegado en casa es la lectura, el deporte, y el esparcimiento así como la jardinería, la carpintería y la cocina. El ocio con las amistades se compone por actividades como el encuentro en restaurantes o bares, convivencias o fiestas. Este ocio tiene una tendencia particular porque su finalidad es el descanso, la sociabilidad y la diversión con las amistades, es una evasión de la cotidianidad y de los compromisos cotidianos.

Las prácticas de ocio de maestras y maestros de reciente ingreso se caracterizan por: 1) un ocio con interés de descanso y sociabilidad; 2) el encuentro se cierra al grupo de amistades. Existen otras prácticas que se realizan con las amistades que, aunque no se despliegan cara a cara, son parte del encuentro, con la singularidad de ser una convivencia virtual (chatear, navegar, enviar mensajes de correo electrónico o por telefonía móvil); por ello, 3) es un ocio mediado por la tecnología; 4) se despliega con amistades en las cafeterías. Es un ocio con una tendencia particular, es la necesidad de comunicar experiencias personales a amistades, es satisfacer las necesidades de afecto y comprensión. Las características del ocio del personal docente con antigüedad se diferencia del personal docente de recién ingreso en dos cualidades principales: 1) actividades genéricas y, 2) la búsqueda de soledad como necesaria para la reflexión.

El ocio de las maestras y los maestros con antigüedad está orientado por una illusio de compromiso social. Compromiso expresado en la participación dentro de organizaciones magisteriales en busca de incidencia política ${ }^{11}$. Actividad que conlleva una conciencia del nosotros -existencia de interés en común según Heller (2002)- y la búsqueda de influir en la configuración de las relaciones existentes. La sensación de sentirse oprimidas y oprimidos por el Estado y las demandas burocráticas del sistema educativo, lleva a maestras y

\footnotetext{
${ }^{10}$ Por comunicación intrapersonal entiéndase aquella que tiene lugar dentro de la persona, en el interior de nosotros mismos, con distintas finalidades (Martín, 1999; 52).

11 "soy representante sindical de mi delegación, participo en comités de política, también participo en campañas electorales, me han invitado a participar para candidata... me gusta apoyar, participar, dar ideas y sugerir" (Entrevista, 11 de marzo de 2009).
} 
maestros a reunirse, entre semana y después de la jornada laboral, para escuchar y expresar ideas, situaciones, esperanzas y proyectos a futuro, leer, informarse, redactar documentos que van dejando huella de su pensamiento y deseo emancipador.

Es un ocio genérico que emerge de una conciencia colectiva, del desprendimiento de los intereses de la persona particular. Surge por la reflexión que se hace de sí mismo como persona particular y como profesionista, desde la experiencia de la vida pública y privada, ya que "La actividad política... nunca puede ser desarrollada con una conciencia cotidiana" (Heller, 2002, p. 296). Es un ocio productivo y genérico que favorece la formación personal y social de las maestras y los maestros ${ }^{12}$, para construir un orden nuevo basado en el conocimiento del sistema educativo y de sí mismo.

La práctica de la actividad política, bien cabe ligarse a la práctica del ocio de la lectura, ya que esta última es un medio de información y formación, por el cual se puede elevar el nivel de conciencia del nosotros. La lectura, dice Roger Chartier (2000), es apropiación e invención, es por ello que la práctica de alguna lectura es un ocio creativo. La lectura es portadora y transmisora de saberes $\operatorname{cotidianos}^{13}$. Aunque no toda lectura enriquece, existen textos que solamente mitologizan la vida cotidiana, llenan de extravagancia y agresividad el saber cotidiano.

Los gustos sobre la lectura presentan las siguientes características: 1) las maestras y los maestros de nuevo ingreso tienen más asiduidad a las prácticas de lectura. El género literario del que gustan es la novela, especialmente de García Márquez del boom latinoamericano y la novela fantástica de Stephenie Meyer; 2) las maestros y las maestros con antigüedad tienen gusto, principalmente, por el género de la dramaturgia, otro tipo de lectura que fomentan son sobre textos de derecho, códigos y leyes ${ }^{14}$, políticas educativas y relacionados con la reforma educativa. Textos que responden a sus necesidades laborales y personales. Ambas generaciones gustan de libros de superación personal. Revisan los

\footnotetext{
${ }^{12}$ Es oportuno aclarar que se hace alusión de una actividad política ajena a las formas de ser y valorar del SNTE (Sindicato Nacional de Trabajadores de la Educación), incluso de la CNTE (Coordinadora Nacional de Trabajadores de la Educación) ala disidente del SNTE. Estos son maestros que buscan nuevas formas de organización social a través de la reflexión y discusión y no solo de paro y la marcha como son las formas tradicionales de manifestación.

${ }_{13}$ Saber cotidiano, es la suma de conocimientos que todo hombre "debe de interiorizar para poder existir y moverse en su ambiente". El saber cotidiano responde al momento histórico y a la posición que se ocupe según la división social del trabajo (Heller, 2002; 526).

${ }_{14}$ Constitución Política de los Estados Unidos Mexicanos, Constitución del Estado de Querétaro, Reglamento de derechos y obligaciones de los trabajadores al servicio del estado.
} 
periódicos locales y nacionales como La Jornada, revistas de divulgación científica como Quo y Conozca más y Muy interesante, revistas que hacen más uso de la imagen que del texto y que alejan del concepto e inhiben la capacidad de reflexión, como lo afirma Sartori (1997).

La cafetería, el jardín o las áreas verdes y la recámara son los espacios preferidos para la lectura. La lectura se acompaña con un café o una cerveza, en el bullicio de la calle o, en la comodidad de la alcoba, casi quedando excluida la biblioteca. La lectura está sujeta al bagaje cultural previamente adquirido, a las razones que llevan a la lectura, a las capacidades de comprensión del lector y de los hábitos lectores ${ }^{15}$. Asimismo, el enriquecimiento del saber cotidiano está determinado por el libro leído. Ello indica que no toda la lectura tiene una orientación creativa y formativa que desemboque en la formación de la conciencia del nosotros y que esté ligada a la práctica de la actividad política.

El arte como ocio es una forma de expresar ideas, emociones y una visión del mundo, algunas maestras y maestros lo hacen por medio de canciones, cuentos para la niñez o por la pintura ${ }^{16}$. La creación de productos hechos en el tiempo libre, fruto de las ideas, emociones, de la percepción que se tiene del mundo, se puede considerar obra de arte ${ }^{17}$. La realidad plasmada adquiere un valor estético, es decir, una pintura o melodía “... adquieren un valor estético cuando subliman las pasiones, las ideas, los sentimientos del hombre que vive en sociedad' (Mendieta, 1980, p. 309). La acción de sublimar lo convierte en una

\footnotetext{
15 "Mi mamá me decía que tenía que leer, aunque fuera un párrafo antes de comer, de jugar y de dormir" (Entrevista, 20 de abril de 2009). "Me gusta leer porque aprendo muchas cosas, y casi leo de todo, porque lo disfruto y porque es una forma de enriquecer a mis alumnos" (Entrevista, 31 de marzo de 2009). "Leo porque me gusta, y lo hago para mí, no me gusta compartir lo que leo con nadie, es para mí" ((Entrevista, 26 de Marzo de 2009). "Hasta que un maestro me dio a leer El Capital de Marx en la normal, me comenzó a gustar la lectura de izquierda, como lo llaman a algunos. Este tipo de libros me ayuda a entender mi mundo y a luchar por la dignificación de la educación" (Entrevista, 23 de marzo de 2009).

16 "compongo canciones y cuentos infantiles y me meto en cuanto concurso hay, escribo para niños y temas para niños... descubrí que puedo pintar y que a través del color puedo sacar sentimientos y sacar cosas bonitas" (Entrevista, 31 de marzo de 2009).

${ }^{17}$ Se emplea la frase creación de arte por el hecho de que la producción esté dentro de los géneros del arte, es decir, de las bellas artes: pintura, música, artes escénicas, escultura, literatura y arquitectura. Asimismo, existe una distinción entre un gusto vulgar y un gusto exquisito que lo hace estético. El maestro que hace producciones artísticas se somete al juicio de un grupo académico que lo juzga y que lo legítima como una obra de arte. Al ser reconocida la producción se puede hablar de producciones artísticas. Una obra solo existe en un campo y en la lucha de éstos y en aquellos que componen el campo y que le atribuyen un valor simbólico y económico. Cfr. Bourdieu, La distinción, 225
} 
objetivación individual y en una actividad genérica porque es la expresión de la autoconciencia, porque plasma la vida entera de las personas.

Es un ocio creador que se comparte con el resto de la sociedad y que se convierte en una manifestación de humanización y, al mismo tiempo, la producción artística es testigo de la historia de la sociedad; producción que se convierte en el espejo del desarrollo de las personas. Práctica que sale de la lógica de la industria del entretenimiento, y algunas maestras y maestros piensan su ocio para producir para la infancia, para ayudarles en su desarrollo personal ${ }^{18}$. Estos espacios favorecen que la maestra y el maestro se concentren en sus ideas y pasiones, lo cual permite suspender cualquier actividad.

Tanto las objetivaciones artísticas como las actividades políticas para que sean momentos de adecuación, o de denuncia de la deshumanización, requieren de poner distancia de sí y del mundo dado, es así que la maestra y el maestro con antigüedad requieren de espacios de soledad. En el tiempo libre, incluso en el tiempo forzado, se dedican espacios para estar en silencio, para meditar en situaciones de la cotidianidad ${ }^{19}$. La búsqueda de soledad es creativa tanto en la forma de buscarla, como en su tendencia de tiempo de ocio. La reflexión es la acción de construir sus propios intereses que reflejan al propio ser social y que están orientados a transformar las relaciones sociales existentes. Esto hace de los momentos de aislamiento un ocio creativo con una tendencia genérica ${ }^{20}$.

Otro tipo de ocio de la esfera personal son los amores. La sociedad moderna ofrece el beneficio de la privacidad. La soledad hace posible que las maestras y los maestros disfruten de los amores en el noviazgo o con la pareja. Amores que satisfacen las necesidades de amor y entrega de las personas. La vida amorosa, en ocasiones responde a necesidades particulares, como son los amores clandestinos, que buscan satisfacer necesidades

\footnotetext{
${ }^{18}$ Enseñarles con música y arte, afirma el maestro: "les da seguridad, les enseña a encontrar lo bello de la naturaleza, de las personas, la riqueza del ser humano, el poder trabajar en equipo, el poder pertenecer a una sociedad, el dignificarse y dignificar al otro, el valorar al otro es valorarse ellos mismos; además se reconocen y dan lo mejor de sí" (Entrevista, 31 de marzo de 2009).

19،... 4 ó 3 de la mañana cuando no hay ni un solo ruido, cuando estoy sola en mi espacio... cuando manejo, voy sola en mi mundo, es mi momento y me dedico a componer o a pensar en mis cosas" (Entrevista, 32 de marzo de 2009).

20 “... busco un lugar en silencio, para pensar en por qué los niños no aprenden, en cómo estoy haciendo las cosas, en cómo seguir trabajando en el movimiento magisterial, también pienso en mi familia y en mis problemas" (Entrevista, 20 de mayo de 2009).
} 
afectivas, en el tiempo de ocio ${ }^{21}$. Estos amores son parte de una necesidad de la extensión de sí mismo. La reputación de tener varias mujeres, en el varón, es parte de incrementar su virilidad y ello es causa de satisfacción particular.

El desarrollo tecnológico en la comunicación forma parte de las formas de sociabilidad. Para algunas maestras y maestros de nuevo ingreso el uso de la Internet y de la telefonía móvil es el medio de comunicación por excelencia ${ }^{22}$. Parte de la comunicación con la familia, las amistades y las personas del trabajo se da mediada por correos electrónicos y mensajería móvil. En ocasiones no es necesaria la presencia física para estar comunicados. Algunos de los correos electrónicos son cadenas con mensajes estandarizados y mensajes de celular con información puntual, alejada de una comunicación cara a cara.

Tal es la influencia de la Internet, que las maestras y los maestros participan en foros (chats) $^{23}$ en los cuales su opinión es emitida sobre conflictos, dudas, sugerencias y opiniones de asuntos personales. El foro chat es una sociabilidad con un vínculo desterritorializado. Puede presentar un lado positivo como es la objetivación de ideas, sentimientos, problemas y proyectos. También se gana el encuentro con otras personas y es una forma de acumular capital social, se ganan nuevas compañías y amistades; aunque no siempre sus tendencias son genéricas. Así mismo puede presentar un lado no tan positivo como ser un ocio programado y aburrido que no lleva a la auténtica comunicación, sino a comunicaciones superfluas y periféricas orientadas por una lógica consumista.

En suma, las prácticas personales de ocio se mueven entre lo cotidiano y lo no cotidiano, entre lo viejo y lo nuevo, entre la reparación de la fuerza de trabajo y la formación humana, entre las exigencias del sistema educativo y la realización de prácticas de libre elección de las maestras y los maestros que lo llevan a la realización personal, entre actividades compensatorias y orientadas por el gusto.

\footnotetext{
21 “.. no me gusta hablar de mi esposa, no nos llevamos bien, y estoy con ella porque cuando le pedí que viviéramos juntos era para siempre y, por eso me aguanto, pero tengo una casa que es mi espacio... y siempre he sido muy discreto en mis relaciones con otras maestras, esa casa es para estar con ellas" (Entrevista, 26 de marzo de 2009).

22 "estoy 2 hrs diarias en el internet, me meto en la página de YuoTube, uso el correo electrónico para comunicarme, a veces envío las cadenas que me mandan amigos, también chateo con mis amigos. El celular me es indispensable para comunicarme, casi todo el día envío mensajes a mi esposo, amigos y compañeros". (Entrevista, 31 de marzo de 2009).

23 "Frecuento foros, chats, porque me gusta opinar sobro asuntos varios, y como no conozco al que hace la pregunta, puedo decir lo que pienso" (Entrevista, 2 de junio de 2009).
} 


\subsection{Vinculación de los estilos de ocio y práctica docente: juego en el aula del capital acumulado en el tiempo de ocio}

Aquello que consideramos privado y restringido a ciertas personas, como familiares, amistades y amores, no tiene fronteras definidas con lo público. La práctica docente requiere de la extensión de lo apropiado en la vida privada y en la vida pública.

Se presenta un vínculo entre ocio y práctica docente por la illusio de ser maestra o maestro. El interés que orienta la práctica docente lleva a la acumulación de capitales. Hay capitales que se acumulan sin tener presente el por qué de ser maestra o maestro. El aula es el espacio social donde el profesorado pone en juego todo el capital acumulado y, parcialmente, deja al descubierto sus gustos. La relación encontrada entre ocio y práctica docente es la siguiente: el estilo de ocio familiar tiene tres formas de práctica docente: 1) maestras y maestros en ciernes, 2) autoritaria y 3) la renuncia a educar; el ocio que se despliega de manera personal se presenta con una práctica docente emancipadora.

\subsubsection{La illusio que les hace ejercer como maestra o maestro, y su vinculación con el ocio}

La illusio que orienta a la actividad educativa es diversa, va desde: a) Educar como la posibilidad de humanizar el mundo, y educando el profesorado se instruye a sí mismo. b) Por compromiso con la nación, para contribuir a la formación de los nuevos ciudadanos y cambiar el rumbo como país. Son maestras y maestros por vocación, por el significado social, por la pasión y compromiso que sienten por la infancia y el país. c) Por herencia del padre maestro, o de la madre maestra. d) Por el gusto a los niños. e) Descubrieron que tenían capacidad para transmitir conocimientos. f) Querían seguir estudiando y la carrera no era costosa. g) Por azar y decisión de los padres de familia. h) Por la seguridad de la plaza al terminar los estudios, convirtiendo la profesión de maestra o maestro en un "comodín".

Tanto el ocio como la práctica docente siguen un mismo estilo de vida. La tendencia al ocio familiar da una práctica docente, en unos casos, autoritaria y en otros, como renuncia a educar. La práctica autoritaria la mueve la ilusio de formar ciudadanos y contribuir con el país. La docencia como modo de sobrevivencia es una práctica que elige la renuncia a educar.

En ambos tipos de prácticas, el ocio es ajeno a la práctica docente, el trabajo y el descanso no tienen vínculo alguno. Las maestras y los maestros en ciernes creen también 
en formar ciudadanos y en contribuir con su país a través de la educación. El ocio está entre lo familiar y personal, sin hacer una separación entre el ocio y el trabajo. El ocio es la oportunidad de formarse para ser mejores profesionistas. La docencia con tendencia emancipadora está orientada a formar a la persona, motivada por la illusio de percibirse maestras y maestros como bastiones de un nuevo orden social y viviendo un ocio personal sin separarlo de la vida laboral. El ocio es parte de transformar el mundo, el aula es un espacio más para vivir sus ideas.

Hilvanar la illusio que sostiene la elección de la docencia como profesión con la descripción de la práctica docente, así como las vivencias de ocio, permiten construir una tipología de modos de ocio-práctica docente. Existe un sentido y un interés que orienta la práctica docente, así como una creencia que de algo vale la pena ser emprendido en el tiempo libre. Esto configura la vinculación entre ocio y práctica docente.

\subsubsection{Ocio aburrido, maestra autoritaria ${ }^{24}$}

Esta maestra hace una separación consciente de su trabajo y vida personal considerándolas ajenas. El ocio es únicamente descanso y demandas familiares. La práctica docente es movida por la illusio de enseñar los conocimientos necesarios para la vida adulta y cumplir con exigencias de programas formativos. La reseña de contenidos es el medio de garantizar la enseñanza; teniendo como pilares el orden y la autoridad que se manifiesta en el control de cuerpos, ideas y silenciamiento del alumno, castigo y reproche. Práctica docente que somete al alumno a su interés particular e inhibe su curiosidad. No todo es negro en su práctica, indirectamente lleva al alumno a ser solidario entre sí, a que exprese sus ideas a pesar del maestro.

\subsubsection{Ocio aburrido, maestro ${ }^{25}$ que renuncian a educar}

El ocio es ajeno a la práctica docente, es tiempo de gozar la vida con amigos, familia y en algunos momentos con los amores. Aquello que se acumula en el tiempo de ocio lo reservan para sí mismo. Su illusio como maestro es formar para la vida adulta. Su trabajo es el medio de sobrevivencia, por eso evaden el conflicto entre él y el sistema educativo y evita

\footnotetext{
${ }^{24}$ Se habla solo de maestra, porque solo se presentó un caso y corresponde al género femenino.

${ }^{25}$ Nuevamente solo se presentó un caso y corresponde a un varón.
} 
el compromiso con la población estudiantil. Se justifica en el orden y prescripciones dadas. Reproduce el texto, se ausenta del salón física y moralmente. Su renuncia a educar lleva a que alumnas y alumnos despierten habilidades para enfrentar sus demandas académicas, así como el desarrollo de su pensamiento autónomo, porque no hay modelo a reproducir de autoridad, esto es una bondad indirecta de su renuncia.

El ocio masificado, en la maestra y en el maestro, aletarga el pensamiento crítico, socava la creatividad, curiosidad y capacidad de reconocer las contradicciones del mundo. Dificulta la autonomía de pensamiento, compromiso social, político y fruición con al arte, además de la búsqueda de su acrecentamiento y fomento en el alumno.

\subsubsection{Ocio creativo, maestra y maestro emancipador}

El ocio está vinculado a la profesión, es la prolongación de asumir su compromiso de educar y transformar, existe en el ocio un sentido de vida. Ambos se reconocen con un compromiso moral y social. En su práctica docente no controla el cuerpo ni las ideas, no silencia, motiva la creatividad y curiosidad del alumno, propicia el diálogo y la escucha. La sombra de esta maestra y maestro es la reproducción que hace, en momentos, del texto, y en otras situaciones recurrir al castigo, así como mimar porque, esto mal acostumbra a la población estudiantil y el trabajo del aula se ve lento. No todo es democrático en el aula.

\subsubsection{Ocio híbrido, maestras y maestros en ciernes}

Esta condición la viven algunas maestras y maestros de recién ingreso. Sienten la pasión por la profesión y en el ocio buscan autoformarse y formarse, los compromisos familiares y personales los alejan de esta intención. Además de ser hijas e hijos de los tiempos modernos, gustan de retraerse del mundo. Reproducen elementos de la escuela tradicional como el orden, el verbalismo y ellas y ellos como autoridad. Fomentan relaciones horizontales en el aula y delegan responsabilidades a la comunidad estudiantil. Es una práctica que comienza el camino de maduración. Práctica que cuenta con la plasticidad para formarse. La población estudiantil siente cercana a la maestra o al maestro. La inseguridad con la que enseñan y educan es la sombra de la maestra y el maestro en ciernes porque la población estudiantil vive en esta ambivalencia de lo viejo y lo nuevo. 
El habitus sí se transfiere a los distintos campos y situaciones de la maestra y el maestro. Un ocio particular y masificado se vincula con una práctica docente de igual forma, y un ocio creativo con una práctica docente genérica.

\section{Pedagogía de la pregunta: propuesta para la vivencia del ocio}

Para que sea posible la realización de la libertad humana en el ocio, es necesario un proceso de emancipación y reivindicación tanto de lo individual como lo comunitario; la tarea es liberarse a sí mismos y liberar a quien oprime como lo propone Freire y Faundez (1985). El malestar es la presencia de la industria del entretenimiento que hace vivir el ocio como letargo y sufrimiento, y el tiempo libre sin importancia: "ya me bañé, ya desayuné, ya leí, ya vi tele y ya no sé qué más hacer y todavía falta para ir a dormir," expresó un maestro. EI aletargamiento y falta de creatividad es la condición de opresión causada por los malestares de la modernidad. Situación que no permite seleccionar lo que realmente es importante y roba el tiempo. El ocio debería ser el espacio para preguntar el por qué del letargo de la falta de alternativas, el tiempo de interrogar al mundo.

Preguntarnos sobre la existencia es el principio del conocimiento y el acercamiento a lo social, todo conocimiento comienza con la pregunta, por la curiosidad, nos dice Freire y Faundez (1985). La pregunta y la curiosidad son la forma de combatir al ocio que repliega del mundo, al ocio particular que satisface necesidades y que alimenta la búsqueda particular de sí mismo, características de la sociedad moderna en donde el único interés es el de uno mismo "... donde la atención se centra estrechamente en la creación de uno mismo, la autoafirmación y la mejora personal' (Bauman, 2009, p. 29). El ocio debe llevar a interrogar la existencia personal y comunitaria, recobrar la curiosidad, el asombro y la creatividad, para no adoptar y adaptarse a la influencia de la cultura de masas y reproducción del mundo dado.

El ocio debe llevar al compromiso personal y comunitario. Una vez que se interrogue a la realidad, esta puede ser reivindicada, porque se pregunta por las necesidades, deseos, anhelos propios y sociales desde la propia experiencia y no por los impuestos por la industria del entretenimiento. Reflexión que lleva a nuevas formas de satisfacción de las necesidades, nuevas formas de organización social y la democratización de la convivencia social. El fruto de un ocio creativo sería no sólo resolver las necesidades particulares, sino también comprometerse con el otro porque el tiempo dedicado al cuidado de alguien “... representa el 
precioso hilo con el que se tejen los lienzos del compromiso y de la unión" (Bauman, 2009, p. 29).

Es necesario romper con el método tradicional de enseñanza, tanto de las maestras y maestros como de la población estudiantil, es necesaria una práctica docente emancipadora que permita despertar y desarrollar en las alumnas y los alumnos habilidades y aptitudes para que puedan potencializar su creatividad y capacidad creadora.

\section{Conclusiones}

Los estudios de caso permiten hacer aproximaciones del fenómeno estudiado. Las cuatro maestras y los cuatro maestros participantes en la investigación son ejemplos distintivos de un contexto más extenso. Los resultados de investigación no son generalidades, son aproximaciones y una posible respuesta al fenómeno del ocio y práctica docente. De ahí que se concluya que estas maestras y estos maestros no sólo son profesionistas cuando están frente a grupo, son personas que ponen al servicio de la comunidad estudiantil todo lo que son: afectos, conocimientos, historia personal y comunitaria, habilidades, aprendizajes, experiencias, ideología y pasiones. De ahí que el ocio sí esté presente en la práctica docente como conocimiento y apropiación de la cultura. El ocio es un elemento más que imprime características a la práctica docente.

La práctica de ciertas actividades de ocio favorece el desarrollo de habilidades sociales, intelectuales, físicas, artísticas y afectivas, que inciden en la capacidad creadora y creativa de maestras y maestros en la práctica docente, condición que los lleva, en la misión de la enseñanza, a enseñar, a buscar y proponer alternativas variadas a las legítimas. Alumnas y alumnos experimentan, prueban y participan de nuevas dinámicas en la relación social al interior del aula; así como de conocimientos que les permiten una lectura del mundo distinta. Un ocio creativo incide en una práctica docente emancipadora, más humanizada, en donde maestras y maestros y la comunidad estudiantil se autorreconocen y reconocen a las demás personas con la misma dignidad humana.

Un ocio que es aburrido y programado por la industria del entretenimiento, deja de ejercitar el pensamiento crítico, la libertad de autoformación y de autorreconocimiento. Es un ocio con realidades opresoras que por ende, lleva a una práctica docente reproductora de las prescripciones del mundo, a la homogeneización de conocimientos y formas de opresión social, por lo que se vuelve autoritaria o renuncia a educar. Un ocio aburrido tiene sus 
contradicciones, por un lado empobrece y aletarga el pensamiento crítico, pero al mismo tiempo fomenta y posibilita la sociabilidad entre las mujeres y los hombres.

La vida privada, como espacio libre de la presión social, es el capullo transformador de la vida entera, porque en ese espacio es donde se aprenden las artes de hacer y existe la posibilidad de ser quien se quiere ser. La vida privada es un espacio de apropiación de toda persona; reconocer las condiciones de existencia y las necesidades, es el punto de partida para hacer lo que se desea en verdad sin seguir las prescripciones del mundo dado. Es necesario educar en el reconocimiento de las necesidades personales y sociales, desde la experiencia personal y no de las impuestas por el sistema consumista.

Tenemos que ser conscientes que maestras y maestros antes de serlo, son personas con formas de ser y valorar que adquirieron en la familia, comunidad, escuela y otras instancias socializadoras. Es necesario que maestras y maestros sean dueños de sí, que reconozcan sus necesidades y la forma de satisfacerlas. El profesorado no por asistir a la escuela normal a formarse son expertos en educar y educarse.

Por último se debe asumir el camino de emancipación y humanización con responsabilidad personal.

\section{Referencias}

Aries, Philippe \& Duby G. (2001). Historia de la vida privada (Vol. 5 De la Primera Guerra Mundial hasta nuestros días). México: Editorial Taurus.

Bauman, Zygmunt. (2005). Los retos de la educación en la modernidad líquida. Barcelona: Editorial Gedisa.

Bauman, Zygmunt. (2007). Vida de consumo. México: Fondo de Cultura Económica.

Bauman, Zygmunt. (2009). El arte de la vida. De la vida como obra de arte. Barcelona: Editorial Paidós.

Bordieu, Pierre. (1990). Sociología y Cultura. México: Grijalbo.

Bourdieu, Pierre. (1991). El Sentido Práctico. Madrid: Taurus humanidades.

Bourdieu, Pierre y Wacquant Loïc, J.D. (1995). Respuestas por una antropología Reflexiva. México: Grijalbo.

Bourdieu, Pierre. (2002). La distinción. Criterio y bases sociales del gusto. México: Editorial Taurus. 
Cuenca Cabeza, Manuel. (2000). Ocio humanista. Dimensiones y manifestaciones actuales del ocio. Barcelona: Instituto de Estudios de Ocio.

Chartier, Roger. (2000). Las revoluciones de la cultura escrita. Diálogos e intervenciones. Barcelona: Editorial Gedisa.

De Certeau, Michel. (1999). La invención de lo cotidiano 2: habitar, cocinar. México: Universidad Iberoamericana.

Freire, Paulo y Faundez, Antonio. (1985). Por uma pedagogía da pergunta. Rio e Janeiro: Paz e terra.

Freire, Paulo. (2002). Pedagogía de la autonomía. Saberes necesarios para la práctica educativa. México: Siglo Veintiuno Editores.

García Canclini, Nestor. (2004). Culturas híbridas. Estrategias para entrar y salir de la modernidad. México: Editorial Grijalbo.

Gómez, Alberto Luís. (1998). Aproximación histórica al estudio de la geografía del ocio. Guía introductoria. España: Anthropos Editorial del Hombre.

Gonzalbo Aizpuru, Pilar. (2006). Introducción a la historia de la vida cotidiana. México: El Colegio de México y Centro de Estudios Históricos.

Gramsci, Antonio. (1981). La alternativa pedagógica. Barcelona: Editorial Fontamara, S.A.

Gramsci, Antonio. (1999). Antología. México: Editores Siglo Veintiuno.

Heller, Ágnes. (1985). Historia y vida cotidiana. Aportaciones a la sociología socialista. México: Grijalbo.

Heller, Ágnes. (2002). Sociología de la vida cotidiana. Barcelona: Ediciones Península.

Husserl, Edmund. (1990). Invitación a la fenomenología. Barcelona: Editorial Paidós.

Lefevre, Henri. (1984). La vida cotidiana en el mundo moderno. Madrid: Alianza Editorial.

Martín, Antonio Lucas. (1999). Sociología de la comunicación. Madrid: Editorial Trotta.

Martí Monterde, Antoni. (2007). Poética del café: un espacio de la modernidad literaria europea. Barcelona: Anagrama.

Martínez Miguélez, Miguel. (1998). La investigación cualitativa etnográfica en educación. México: Trillas.

Mendieta y Nuñez, Lucio. (1980). Sociología del arte. México: UNAM 
Mercado, Ruth e Elsie, Rockwell. (1986). La escuela, lugar del trabajo docente. Descripciones y debates. México: DIE/Cinvestav/IPN.

Morín, Edgar. (2002). La educación del futuro. París: UNESCO.

Orozco Gómez, Guillermo. (2000). La investigación en comunicación desde la perspectiva cualitativa. México: Instituto Mexicano para el Desarrollo Comunitario, A.C.

Pansza, Margarita, Pérez C., Esther, y Morán Porfirio. (1993). Fundamentación de la didáctica. México: Gernika.

Requena Santos, Félix. (1994). Amigos y redes sociales. Elementos para una sociología de la amistad. Madrid: FCE.

Rueda Beltrán, Mario. (1991). El aula universitaria. Aproximaciones metodológicas. México: UNAM.

Sartori, Giovanni. (1997). Homo videns. La sociedad teledirigida. México: Punto de lectura.

Sue, Roger. (1992). El ocio. México: Fondo de Cultura Económica: Breviarios

Weber, Max. (1982). Ensayos sobre metodología sociológica. Buenos Aires: Amorrortu editores.

Weber, Max. (1985). La Ética Protestante y el Espíritu del Capitalismo. México: Premiá editora.

Weber, Max. (2002). Economía y sociedad. México: Fondo de Cultura Económica 